\title{
Independent Auditors as Fiscal Gatekeepers
}

\author{
Luigi Alberto Franzoni*† \\ Department of Economics, University of Bologna \\ January 1996
}

\begin{abstract}
This paper develops a framework for the analysis of gatekeeping in tax enforcement, whereby independent auditors are assigned the duty of certifying taxpayers' reports. The equilibrium of the market for gatekeepers' services is characterized, as well as taxpayers' and auditors' optimal behavior. The paper discusses the optimal structure of the gatekeeping regime and determines the conditions under which it is socially preferable to direct public enforcement.
\end{abstract}

JEL Nos. K42 (Illegal Behavior and the Enforcement of Law) and H26 (Tax Evasion).

Keywords: Law enforcement, tax evasion, auditing, collateral liability, certification.

* Correspondence to: Luigi Alberto Franzoni, Dept. of Economics, P.zza Scaravilli 2, 40126 Bologna, Italy. E-mail: lfranzoni@ecn01.economia.unibo.it

† I am grateful to Luigi Bernardi for bringing to my attention the problem dealt with in the paper, to Gianluigi Albano and participants to the FEEM conference on "Pressure Groups, SelfRegulation and Collective Decision Making" for helpful comments, and to Fondazione Eni Enrico Mattei for financial support. 


\section{Contents}

1 Introduction : : : : : : : : : : : : : : : : : : : : : : : : : : : : 3

2 The model : : : : : : : : : : : : : : : : : : : : : : : : : : : : : : : 8

2.1 The demand for audits : : : : : : : : : : : : : : : : : : : : : : : 10

2.2 The equilibrium of the audit market $::::::::::::::::::$ : 11

3 Comparison of regimes : : : : : : : : : : : : : : : : : : : : : : 16

4 Extensions : : : : : : : : : : : : : : : : : : : : : : : : : : : : : : : : : 18

4.1 Collusion : : : : : : : : : : : : : : : : : : : : : : : : : : : : : : : 18

4.2 Strict liability versus negligence : : : : : : : : : : : : : : : : : : : : : 19

4.3 Gatekeeping versus full delegation $::::::::::::::::::$ : : 22

4.4 Cartelization in the audit market $::::::::::::::::::$ : $: 23$

5 Final remarks : : : : : : : : : : : : : : : : : : : : : : : : : : : : : 24

6 Appendix : : : : : : : : : : : : : : : : : : : : : : : : : : : : : : 26 


\section{Introduction}

In many enforcement settings, collateral liability is imposed on third parties who are not the primary authors of the misconduct, nor the direct beneficiaries, but may nevertheless play an important part in preventing it. Using the terminology of Kraakman (1986), we call "gatekeeper liability," the liability imposed on third parties who are entrusted with the duty to "disrupt misconduct by withholding their cooperation from wrongdoers." Gatekeepers' liabilities are extremely widespread and range from that imposed on intermediaries who certify production standards or product quality (e.g. compliance certification with respect to ISO, IMQ, environmental regulations, etc.), to the liability imposed on accountants and lawyers in securities transactions with regard to their opinions (SEC regulations), and include the liability imposed on employers with regard to the violations of their employees, and the liability of doctors and pharmacists in preventing drug abuse.

The aim of this paper is to examine whether the introduction of a secondary control system can provide a solution to the difficulties met by many public agencies in the enforcement of tax law. In particular, we will analyze the properties of a gatekeeping system in which taxpayers who claim not to be liable need to have their tax return certified by an independent auditor. Auditors, in turn, are profit-motivated agents and compete on the audit market. The use of such an enforcement device raises important issues, which we will address in the paper, such as: How is taxpayers' behavior affected by the certification system? When is a gatekeeping system likely to be superior to the simple alternative of direct public enforcement? What is the optimal structure of the gatekeeper liability? Is a gatekeeping system vulnerable to collusive behavior by the agents?

The general theme of collateral liability has attracted the attention of legal scholars for a long time. ${ }^{1}$ In his fundamental work, Kraakman (1986) provides an extensive analysis of the purposes served by collateral liability in the enforcement of law, and presents an informal discussion of its benefits and costs. The author comes to the natural conclusion that the desirability of gatekeeping essentially depends on the context of its application. In particular, he suggests that: "Successful gatekeeping is likely to require (1) serious misconduct that practicable penalties cannot deter; (2) missing or inadequate private gatekeeping incentives; (3) gatekeepers who can and

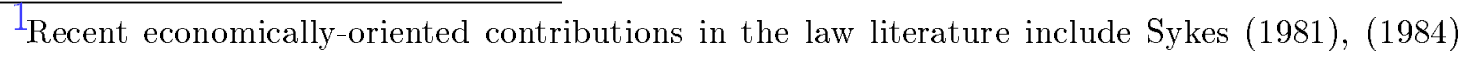
and (1988), and Kraakman (1984) and (1986).
} 
will prevent misconduct reliably; and (4) gatekeepers whom legal rules can induce to detect misconduct at reasonable cost".

This paper extends Kraakman's analysis by providing a precise content to the previous statement and by investigating other important issues relating to a gatekeeping system, such as those associated with the properties of the equilibrium of the market for gatekeeping services and the desirability of further delegation of the enforcement functions. Although the focus will be on the enforcement of tax legislation, the insights provided apply to a vast gamut of regulatory problems, in which enforcement can involve both public and private actors.

We model the enforcement problem as one in which individuals who share some predetermined characteristics are subject to a fixed tax. The relevant characteristics are private information to individuals and can be observed only through a costly audit. Random audits are preformed by a public enforcement agency, which however lacks the capacity to induce full compliance on the part of taxpayers. The state then faces the option of using private auditors as gatekeepers, and imposing mandatory auditing on taxpayers who want to be exempted for the tax. This requires a specific collateral liability to be imposed on auditors, in order for them to be motivated to detect illegitimate claims.

The paper characterizes the optimal behavior of taxpayers and private auditors in the gatekeepers' regime, assuming that the latter compete à la Bertrand on the audit market. ${ }^{2}$ As expected, the introduction of a gatekeepers' regime turns out to be desirable only if certain conditions are satisfied. In particular, gatekeeping is proved to increase social welfare only if: i) the collateral liability of private auditors is sufficiently large, or ii) the private audit cost is sufficiently small. In other words, private gatekeeping represents an effective enforcement tool only when gatekeepers can be sufficiently motivated (high liability) or when they enjoy significant informational advantages (low audit cost). Upon closer scrutiny, however, it is the second factor that turns out to play the major role: we show that even if gatekeeper liability is stretched to infinity, gatekeeping is desirable only if the private audit cost is sufficiently small.

Despite its pervasiveness in legal institutions, gatekeeping has been surprisingly neglected by the economic literature on optimal law enforcement. Since the publication of the influential article by Becker and Stigler (1974), the issue of third party

\footnotetext{
"The assumption that the relation between taxpayers and auditors is mediated by the market prevents the use of the mechanism design techniques, and forces a more "speculative" approach to model building. Auditing models based on the revelation principle (focusing on issues different from those addressed by this paper) can be found in Baiman, Evans and Noel (1987) and Strausz (1995).
} 
enforcement has mainly gravitated around whether private enforcers would outperform public ones. ${ }^{3}$ Privatization, however, represents an extreme case of third party involvement, in which the power to detect and sanction wrongdoers is completely delegated to the private sector. Still, the results of this strand of literature are illuminating. Polinsky (1980) compares private enforcement with public enforcement in a model in which individuals can engage in harmful activities. He comes to the conclusion that any enforcement method may be socially preferable, depending on the costs of each method as well as the level of harm associated with wrongdoing. His main point is that, even though public enforcement may involve greater costs, it may still be desirable, as it is not subject to the profit constraint, and can hence result in strong deterrence programmes which yield a very small penalty recovery. Indeed, since private enforcers' profits depend on successful crime detection, one cannot expect them to produce high levels of deterrence, for this would bring their intakes down to nought. As it will become clear below, a similar argument applies to gatekeepers. Under the assumption that their payment cannot be made contingent on the level of effort exerted in auditing, but just on the results of their activity, gatekeepers can be given an incentive to perform thorough auditing only when taxpayers are likely to have misreported. Hence, one cannot have intense auditing and a high level of compliance at the same time.

It is important to distinguish gatekeeping from another form of third-party involvement in law enforcement, namely "whistle-blowing," which requires third parties to report to the authorities illegal acts they have knowledge of. While gatekeeping is based on preventive monitoring ("interdict misconduct"), whistle-blowing is based on ex-post monitoring ("disclose misconduct"), i.e. on the duty to disclose acts of misconduct when they have already been perpetrated. Also, whistle-blowing does not usually require a specific investigative effort by the third-party.

An important example of gatekeeper liability is that placed on private auditors by security regulations, which require many transactions to be subject to mandatory legal opinions. The role of auditors has been subject to a thorough analysis in the accounting literature, where special attention has been devoted to the fiduciary relationship between auditors and shareholders. The focus of this paper is somewhat different, since here auditors are assumed to be subservient to the public rather than the private interest. Also, in this "public" setting, auditors' failures to detect individuals' misreports can be discovered only via costly auditing by the public authority, while in the "private" setting they result in incorrect decisions on the part of the

\footnotetext{
See, for instance, Landes and Posner (1975), Friedman (1984), Polinsky (1980), Melumad and Mookherjee (1989), and Toma and Toma (1992).
} 
shareholders, which may eventually lead to unexpected losses. In the latter case, inaccurate auditing manifests itself with a positive probability even if the "principal" does not engage in double checking, and standard civil liability may in theory suffice to motivate wayward auditors.

Finally, it is important to draw attention to another class of third parties usually involved in the enforcement of law, namely that of legal advisors. Their role is essentially that of providing the principal actor with information about the relevant laws and regulations, and the way in which the actor's behavior can be fitted within the legal grids. Legal advisors are an important element in the enforcement of complex matters such as those related to tax, security and environmental regulation. Given their strong ties with the principal actor and their legal expertise, lawyers and CPAs are in an ideal position to bear gatekeepers' responsibilities. ${ }^{4}$ Legal advising, however, is not the focus of this paper, and we eschew this issue by assuming that the taxpayer is perfectly informed about his true tax liability. ${ }^{5}$

The different strands of literature mentioned above provide different insights on the optimal structure of a gatekeepers' regime. To clear the view from possible confusion, it may be helpful to review the different functions that gatekeepers may be deemed to serve, sometimes improperly, in the enforcement system.

a: Privatizing enforcement. Since it provides an institutional role to marketoriented agents, gatekeeping represents a mild form of privatization of the enforcement system. Privatization, however, is not complete, since the ultimate control remains in the hands of the public enforcer. Also, gatekeepers are usually not empowered with the faculty to impose sanctions, since their main objective is "prevention".

b. Providing valuable information. Gatekeepers acquire information on auditees and convey it to the public authority. In this perspective, the function of gatekeepers can be assimilated to the sale of a "signal" to the public enforcer. Their involvement would hence be desirable when the value of the signal exceeded its cost. This view, however, is over-simplistic as it does not consider the relation between the effort exerted by independent auditors and the rate of control by the public enforcer, as well as the market-based relation between individuals and auditors.

\footnotetext{
${ }^{4}$ Gatekeeping duties of variable degree are assigned to CPAs and lawyers in nearly all countries. See Eörsi (1975) for a comparative view on vicarious liability, and Developments in the law (1994) for an examination of the liability of lawyers and CPAs in the US.

${ }^{5}$ With reference to the US experience, Klepper and Nagin (1989) and Klepper, Mazur and Nagin (1991) show that tax preparers' impact on US taxpayers essentially depends on the type of issue considered: they seem to encourage compliance with regard to unequivocal items and discourage it with regard to ambiguous ones. On the effect of tax advisors on tax complance see also Scotchmer (1989) and Reinganum and Wilde (1991).
} 
c. Shifting the burden of proof. Gatekeeping shifts the burden of proof from the public authority to individuals, who have to prove (through an auditor's certificate) that they are not liable. Such a device is particularly apt when the "proof" cannot take the form of (hard) documentary evidence, and hence cannot be directly produced by individuals. A liability on gatekeepers is imposed so as to discourage the production of incorrect reports (false evidence). ${ }^{6}$ The actual cost of the proof (the audit fee), however, need not necessarily be borne by individuals. Indeed, in welfaremaximizing tax systems, compliance costs are ultimately borne by the state (which has to forgo an equivalent amount of tax revenue), whereas noncompliance costs are borne by individuals.

d. Facilitating self-reporting. Gatekeepers may be deemed to perform the function of helping individuals learn their actual liability level and behave accordingly. In other words, they allow individuals to correctly self-report their behavior. ${ }^{7}$ This view, however, is misleading, as it mixes the role of gatekeepers with that of expert advisors. Since the relation between advisors and their clients is one regulated by the principle of mutual benefit, there is no special reason to subject it to public regulation. This said, it is clear that expert advising and gatekeeping can be efficiently performed by the same party, as an economy of scope is presumably obtained when these tasks are carried out together.

e. Shifting the responsibility. Since the gatekeeper is collaterally liable for acts of misconduct by the principal actor, gatekeeping may be viewed as a device apt to shift the responsibility for law compliance on the party which is more vulnerable to sanctions (either because it owns greater wealth or because it is more concerned about reputation effects). Greater vulnerably in turn implies greater deterrence and higher compliance. We will refer to this argument as the "deep-pockets" theory. ${ }^{8}$ The starting point is clearly the principal actor's asset insufficiency: the maximal sanction that he can bear is insufficient to generate deterrence. Deterrence can then be increased, leaving the control rate unchanged, by expanding the liability associated with misconduct to a third party with deep pockets. ${ }^{9}$ It is important to note, how-

\footnotetext{
In a sense, the core problem underlying the literature on independent auditors is just how to make their reports credible. In the words of Gjesdal (1981): "The fact that hardness is a desirable characteristic of information systems opens up the question of how information systems which are not hard may be made hard at a cost."

${ }^{7}$ Allowing for self-reporting is generally optimal in law enforcement. See Reinganum and Wilde (1985) and Kaplow and Shavell (1994).

${ }^{8}$ Apparently, this was one of the arguments for the stringent liability rules ("joint and several") applicable to accounting firms in the US up to 1996. In fact, accounting firms served the role of "deep-pocket defendants" in civil suits against bankrupt firms. For an analysis of different liability rules for auditors, see for instance Dye (1993) and Narayan (1994).

9n a sense, this is like requiring gatekeepers to provide primary actors with insurance against
} 
ever, that liability and decision power do not usually coincide. In fact, the decision whether or not to abide by the law is not fully delegated to the wealthiest party, nor is it fully "joint," since gatekeepers cannot usually stop compliance-prone individuals from abiding by the law. More specifically, while misconduct is supposed to require the consent of both parties, the principal actor and the gatekeeper, proper conduct can be forced by either party independently of the other. ${ }^{10}$

This paper explores the implications of mandatory certification in an enforcement set-up which allows for self-reporting of behavior by individuals. Gatekeepers are assumed not to possess exclusive legal competence, and they have ex ante less information than their clients. The primary function of gatekeepers turns out to be that of providing an obstacle to misconduct: liable taxpayers who try to get away with their obligation run the risk of being discovered by the gatekeeper and paying for their failed attempt (wasting money on the audit fee). In this sense, gatekeeping results in a shift in the burden of "proof" from the state to taxpayers.

There now follows a brief overview of the paper. Section 2 introduces the model and presents a full characterization of the agents' equilibrium behavior. In Section 3 , the social desirability of the gatekeepers' system is assessed by comparing it with direct public enforcement. Section 4 introduces some important extensions, like the possibility of collusion (4.1), the effect of a tight negligence standard for auditors (4.2), the desirability of further delegation of the enforcement functions (4.3), and the effect of cartelization in the audit market (4.4). Section 5 provides a summary and some final remarks.

\section{The model}

Let us consider the problem related to the enforcement of a particular fiscal law, which states that taxpayers who fulfill certain prerequisites are liable the amount $T$ : The tax law is assumed to be clearly stated, so as not to leave any ambiguity on the actual criteria for the determination of the liability. In a formal sense, the tax law is assumed to partition taxpayers' type space $\Omega$ in two subregions: N L (non liable)

liability in excess of their wealth. For this service, they are paid a premium (the audit fee), which covers their monitoring costs and expected payments. The specific feature of gatekeeping, as opposed to a simple insurance scheme, rests in the gatekeepers' monitoring vocation: they are capable of, and have a specific interest in, screening out individuals who might cause them to incur a sanction, thereby frustrating attempts to circumvent the law.

${ }^{10}$ Clearly, this is true when the principal actor is not subjugated by the gatekeeper. The principal actor has to be protected from the gatekeeper's malevolent intentions, for example through the right to appeal directly to the authorities. 
and L (liable). The probability measure of the set N L is assumed to be equal to p: The dimensions of this space may relate to the characteristics of the taxpayer's business, such as its turnover, the number of employees, the production technology, etc. These characteristics are private information to taxpayers and can be observed only through a costly audit. ${ }^{11}$ Taxpayers who claim not to be liable are subject to mandatory auditing. Independent auditor are therefore the gatekeepers of the tax law: exemption from the tax can be obtained only through a non-liability certificate issued by the auditor. Auditors are hired on the audit market and are paid an audit fee q: We assume that when an auditor is hired, the taxpayer is committed to accept her final report (hence, the taxpayers cannot switch to a different auditor when the incumbent provides an adverse report). On the other hand, the auditor cannot refuse to issue a report, and is therefore obliged to provide a conclusive opinion either in favor of the Liability or the Non Liability of the taxpayer.

In order to find out taxpayer's real type, the auditor can review all taxpayer's records and perform on-site investigations. Depending on the level of effort exerted by the auditor, the audit will achieve different levels of accuracy. For the sake of simplicity, we assume that the auditor either learns the taxpayer's exact type (an element in $\Omega$ ) or learns nothing. Let a be the probability that the audit reveals taxpayer's true type, and call a the "quality" of the audit. Since the auditing effort is not observable, its level will be decided by each auditor once her opinion has been solicited. The audit fee, on the other hand, is fixed before the audit takes place and is determined on the audit market, where auditing firms supply their services.

Taxpayers who obtain a Non Liability certificate are exempted from paying the $\operatorname{tax} \mathrm{T}$, but may be subject to a second audit by the tax agency with probability ff. If the latter reveals that, contrary to the auditor's opinion, the taxpayer is actually liable, both the taxpayer and his auditor are liable for breach of the tax law and are subject to monetary sanctions $F$ and $P$; respectively. The auditor is hence subject to a strict liability standard, under which she is held liable in the event of a failure to detect a misreport. ${ }^{12}$

An important assumption is that the auditor cannot deny a non-liability certificate when she has found no proofs of the liability of the taxpayer. This implies that she

\footnotetext{
${ }^{11}$ In reality, taxpayers themselves may not originally know whether they are liable or not, but can obtain the relevant information from well informed tax practitioners, whose services can be easily obtained on the market.

${ }^{12}$ Although alternative sanction may be available for the punishment of inaccurate auditors, such as suspension, removal or even imprisonment, a monetary sanction is preferable, since it yields a direct intake to the state. Nonmonetary sanctions may be possibly imposed on top of the fine. On the optimal combination of monetary and nonmonetary sanctions, see Polinsky and Shavell (1984).
} 
cannot "extort" money from non-liable taxpayers by threatening an adverse report. Such a possibility would be prevented, for instance, by allowing taxpayers to appeal the report to the tax agency on payment of a small fee. Once the appeal is issued, the tax agency would perform a new audit on the taxpayer and, assuming that the tax agency itself does not commit first-type errors (false positives), non-liable taxpayers would be relieved from the tax burden.

The timing of the game is the following:

1. taxpayers get to know their true type,

2. taxpayers formulate their demand for audit certificates;

3. anditors compete on the audit market and an equilibrium price is achieved;

4. audits are carried out, of the quality decided by individual auditors;

5. taxpayers who fail to get a non-liability certificate pay the tax T; while the others are subject to a second audit by the tax agency with probability ff;

6 . if the second audit detects a misreport, both the taxpayer and the auditor are sanctioned.

The game is solved through the Bayes-Nash equilibrium concept. We begin the analysis by considering the demand side of the market.

\subsection{The dem and for audits}

While taxpayers who are Non Liable will clearly make use of an auditor, taxpayers who are Liable will do so only if this gives them a good chance to get away with their tax liability. The audit fee is q; and is fixed by the market. One can conceive several possible scenarios regarding the way in which this burden is allocated: i) each taxpayers bears his audit fee, ii) the state refunds the audit fee to all taxpayers, iii) the state refunds the audit fee to taxpayers who have succeeded in obtaining a non-liability certificate.

Among the three possibilities, the most appealing in terms of enforcement efficiency is the third: by making the refund conditional on the outcome of the audit, it creates a specific audit cost for liable taxpayers who pretend not to be so. Liable taxpayers would thus be discouraged from undergoing a costly private audit, and the scope for self-reporting would be retained. This solution dominates the first (in which self-reporting is preserved but at the expense of an increase in the compliance costs for non-liable taxpayers) and the second (compliance costs do not increase, but self-reporting is discouraged).

Let us assume therefore that the audit fee $q$ is refunded by the state whenever the 
auditor's report is "non-liable". Liable taxpayers will make use of an auditor only if

$$
\mathrm{T}^{\vee} \mathrm{a}(\mathrm{q}+\mathrm{T})+(1 \Gamma \mathrm{a}) \mathrm{ff} \mathrm{F}:
$$

By using the auditor, liable taxpayers save on the tax $\mathrm{T}$; but run the risk of being caught either by the auditor (and pay $q+T$ ) or, when this is not the case, by the tax agency (and pay F). Note that liable taxpayers will surely not demand an audit when their expected sanction under public enforcement is a sufficient deterrent, i. e. when ffF \& T: In the opposite case, they will demand a private audit either if the audit is of low quality or is relatively cheap.

In order to provide a rationale for the gatekeeping system, we will henceforth assume that public enforcement is not a sufficient deterrent.

Assumption 1 Insufficient public deterrence: ffF i T:

This assumption implies that taxpayer's expropriable asset is not large enough to be efficaciously used as a collateral.

Let $f i$ be the probability that a liable taxpayer decides to apply for a non-liability certificate. The demand for private audits will be equal to $D(q ; a)=p+(1 \Gamma p) f$, and will range from $p$ to 1 depending on the magnitude of $q$ and $a$ :

\subsection{The equilibrium of the audit m arket}

Let us turn to auditors and their role within the enforcement system. We need to determine the equilibrium price of the auditors' services and the optimal investigation effort that each of them will exert once engaged in auditing. We will develop a model of competition à la Bertrand, in which firms simultaneously decide the price for their service. Auditing firms cannot commit themselves ex ante to any level of auditing effort, since this is not observable. They will therefore choose the effort level (and, consequently, the audit quality) once they have signed the contract with the taxpayer. It is assumed that the effort cost $\mathrm{S}$ associated with an audit is linear in its quality: $\mathrm{S}=\mathrm{s}$ a; where $\mathrm{s}$ is the marginal audit cost.

Let us consider the problem of the auditor. The profit associated with each audit can be written as

$$
\Pi=q \Gamma \text { s a } \Gamma(1 \Gamma \text { a }) \frac{(1 \Gamma p) f i}{(1 \Gamma p) f i+p} f
$$

which includes the audit price q; less the audit cost sa; less the expected penalty associated with a misreport. 
Differentiating with respect to the audit quality a yields

$$
\Pi_{\mathrm{a}}^{0}=\Gamma \mathrm{s}+\frac{(1 \Gamma \mathrm{p}) \mathrm{fi}}{(1 \Gamma \mathrm{p}) \mathrm{fi}+\mathrm{p}} \mathrm{f} \mathrm{P}:
$$

Hence, depending on the probability that the auditee is liable or not, the auditor's auditing effort will be

$$
\begin{aligned}
& { }_{i}{ }^{\Lambda}(f i)=0 \quad \text { if }(1 \Gamma \mathrm{p})(\mathrm{fPP} \Gamma \mathrm{s}) \mathrm{fi}_{\mathrm{i}} \mathrm{ps} \text {; } \\
& a^{\Lambda}(f i) 2[0 ; 1] \text { if }(1 \Gamma \mathrm{p})(f \mathrm{fP} \Gamma \mathrm{s}) \mathrm{fi}=\mathrm{ps} \text {; } \\
& \text { i }{ }^{a} \Lambda(f i)=1 \text { if }(1 \Gamma \mathrm{p})(\mathrm{ffP} \Gamma \mathrm{s}) \mathrm{fi}_{i} \mathrm{ps} \text { : }
\end{aligned}
$$

Note that when the (marginal) audit cost is high, s \& (1 $\Gamma \mathrm{p}) \mathrm{ffP}$; then the expected sanction associated with an erroneous certification is insufficient to motivate accurate auditing, and hence ${ }^{a} \Lambda(f i)=0$ for all fi $2[0 ; 1]$. In the opposite case, there is a threshold value of $f i$ which makes the auditing effort worthwhile: for fi $i \frac{p}{\text { If }}$ ifis (i.e. the taxpayer is likely to be non liable), the auditor will elect to devote no effort to the auditing activity, since the cost of performing an accurate audit outweighs the expected sanction associated with an inaccurate report. Note, finally, that the optimal audit quality does not directly depend on q (if not through fi):

The expected cost of an audit is: $\mathrm{s}$ a $+(1 \Gamma$ a $) \frac{(1 \Gamma \mathrm{p})(\mathrm{f}}{(\mathrm{I} \mathrm{p}) \mathrm{f}+\mathrm{p}} \mathrm{ff}$ P; and, hence, at the optimum:

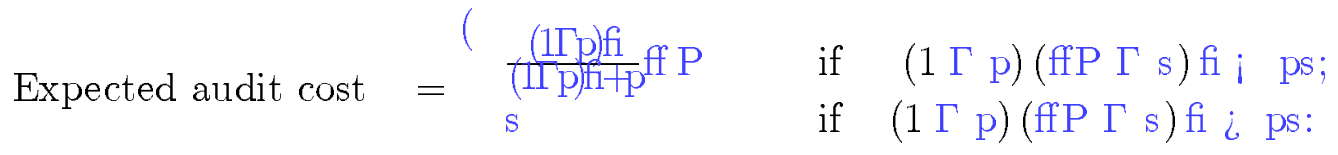

Since there are no returns from scale associated with the number of audits performed by each individual firm (each audit is independent of the other) and all firms are identical, in equilibrium they will all charge a price q equal to the expected unit cost of an audit.

In equilibrium, we will therefore have

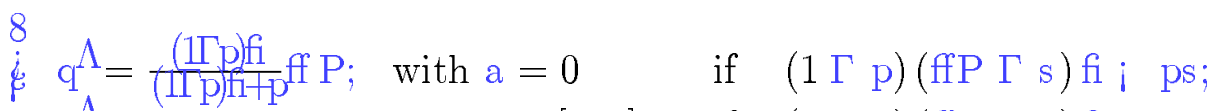

$$
\begin{aligned}
& \begin{array}{llll}
\mathrm{q}^{\Lambda}=\mathrm{s} ; & \text { with a } 2[0 ; 1] & \text { if } & (1 \Gamma \mathrm{p})(\mathrm{fP} \Gamma \mathrm{s}) \mathrm{fi}=\mathrm{ps} ; \\
\mathrm{q}^{\Lambda}=\mathrm{s} ; & \text { with } \mathrm{a}=1 & \text { if } \quad(1 \Gamma \mathrm{p})(\mathrm{fP} \Gamma \mathrm{s}) \mathrm{fi} i \mathrm{ps}
\end{array}
\end{aligned}
$$

Given this audit fee, each auditor breaks even and is willing to undertake as many audits as requested. 13

The audit fee q; together with the expected audit quality a; determines the demand for audits, which, in equilibrium, has be equal to its supply.

By putting together demand and supply, we obtain the equilibrium of the game.

\footnotetext{
${ }^{13}$ As in the standard Bertrand setting, the number of firms operating in equilibrium, as well as their market shares, is indeterminate.
} 
Proposition 1

Gatekeeper may play a role in enforcement only if public deterrence is insufficient (ff $i \frac{T}{F}$ ). If this is the case, the equilibrium of the enforcement game is characterized as follows:

1. Auditors are motivated. If $s i$ ff $(1 \Gamma \mathrm{p}) \mathrm{P}$; then a fraction $\mathrm{fi}^{\Lambda}=\frac{\mathrm{p}}{\mathrm{T} p \mathrm{p}} \mathrm{s} T \mathrm{~s}$ of liable taxpayers demand a private audit, the market audit fee is $q^{\Lambda}=s$, and auditors exert an auditing effort which allows them to detect a misreport with probability a ${ }^{\Lambda}=$ $\frac{\text { TIfFF }}{\text { TIPAF }}$

2. Auditors are not motivated. If $s$ i ff $(1 \Gamma \mathrm{p}) \mathrm{P}$, then all liable taxpayers demand a private audit, $f^{\Lambda}=1$; the market andit fee is $q^{\Lambda}=(1 \Gamma \mathrm{p}) \mathrm{ffP}$, and auditors exert no effort in auditing, $a^{\Lambda}=0$ :

Proof. If ffF \& T; then tax agency's controls are sufficient to deter inaccurate reporting by the taxpayer. Hence, liable taxpayers will not apply for a certification and auditors will face only non-liable taxpayers. Auditors will therefore issue nonliability certificates without exerting any audit effort.

1. If $\underset{(\Pi \mathrm{P}) \mathrm{P}}{\mathrm{S}}$ ff $i \frac{\mathrm{T}}{\mathrm{F}}$; then no-auditing on the side of auditors would induce all liable taxpayers to apply for a certificate, $f(=1$ : But then no-auditing would not be the best strategy for auditors, since the (marginal) expected sanction due to inaccurate auditing, $(1 \Gamma \mathrm{p}) \mathrm{ff} \mathrm{P}$; would exceed the (marginal) audit cost, s: Hence, $a=0$ cannot occur in equilibrium. Consider now the case with $a=1$ : Here, audits are performed with an absolute accuracy and liable taxpayers have no chances of getting to get away with their tax liability (and audit fee). They will therefore not apply for a certification, $\mathrm{f}=0$ : Under this condition, however, auditors would know with certainty that their clients are non-liable and absolute accuracy would not be the best auditing policy. Hence, $a=1$ cannot occur in equilibrium. This proves that, in equilibrium, a and $f i$ have to lie on the interior, and hence that $f^{\Lambda}=\frac{\mathrm{p}}{\mathrm{I}} \mathrm{s}$ s and $a^{\Lambda}=\frac{T H A F}{T H F+c f}$ : Since competition à la Bertrand pushes the audit fee down to the (unit) audit cost, in equilibrium we will have $\mathrm{q}^{\Lambda}=\frac{(1 \Gamma \mathrm{p}) \mathrm{f} \Lambda}{(\mathrm{II}) \mathrm{p}) \mathrm{ff}} \mathrm{P}=\mathrm{s}$ :

2. If $\mathrm{ff}_{i} \frac{\mathrm{S}}{(\Pi \mathrm{p}) \mathrm{P}}$ and $\mathrm{ff}_{i} \frac{\mathrm{T}}{\mathrm{F}}$; then auditors prefer not to engage in costly auditing even if all liable taxpayers apply for a certification with probability one $(\mathrm{f}=1)$ : Since they know that they will not be detected by auditors, liable taxpayers will indeed apply for a certificate: The equilibrium audit fee will just cover auditors' expected sanction, $\mathrm{q}^{\Lambda}=(1 \Gamma \mathrm{p})$ ffP:

Auditors exert a positive function in the enforcement system only when two conditions are satisfied: i) perfect direct enforcement is not viable, ii) the tax agency's 
control activity is intense enough to motivate a positive auditing effort on the part of auditors. The second condition implies that private auditing cannot fully substitute public auditing, since auditors' services are effective only in the presence of the tax agency's stick.

For the purpose of the analysis, we will henceforth concentrate on case 1 of the

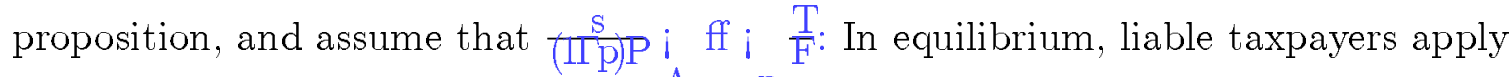
for an audit report with probability $\mathrm{fi}^{\Lambda}=\frac{\mathrm{p}}{\Pi \mathrm{p} \text { ffis }}$; which increases with the audit cost s; and decreases with the expected punishment for incorrect reporting, ffP: As for the

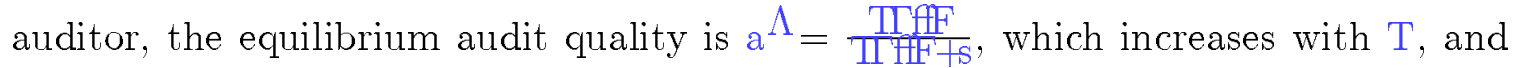
decreases with the audit cost $\mathrm{s}$ and the penalty F: Given the probability of liability of taxpayers applying for an audit and the prospective equilibrium audit effort, the equilibrium market price for the audit service is equal to the marginal audit cost, $\mathrm{q}^{\Lambda}=\mathrm{s}$ : This is the price which allows the auditing firm to break even (in expected terms, and in real terms if it has a large enough number of clients).

We can now turn to the tax agency's net revenue. We have

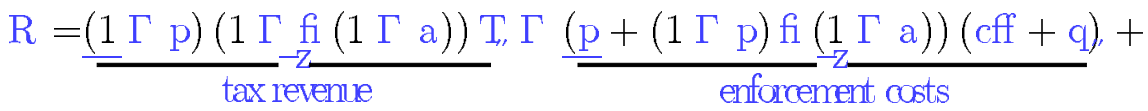

$$
\begin{aligned}
& +\frac{(1 \Gamma \mathrm{p}) \mathrm{fi}(1 \Gamma \mathrm{a}) \mathrm{ff}(\mathrm{P}+\mathrm{F})}{\text { penalty intake }}
\end{aligned}
$$

so that, in equilibrium,

$$
\mathrm{R}^{\Lambda}=(1 \Gamma \mathrm{p}) \mathrm{T} \Gamma \operatorname{pcff} \Gamma \mathrm{ps} \Gamma(1 \Gamma \mathrm{p}) \mathrm{fi}^{\Lambda}\left(1 \Gamma \mathrm{a}^{\Lambda}\right)[\mathrm{T} \Gamma \mathrm{ff}(\mathrm{F}+\mathrm{P})+\mathrm{cff}+\mathrm{s}]
$$

with

$$
\mathrm{fi}^{\Lambda}\left(1 \Gamma \mathrm{a}^{\Lambda}\right)=\frac{\mathrm{p}}{1 \Gamma \mathrm{p}} \frac{\mathrm{s}}{\mathrm{ffP} \Gamma \mathrm{s}} \quad \frac{\mathrm{s}}{\mathrm{T} \Gamma \mathrm{ffF}+\mathrm{s}}:
$$

Note that the sign of the term within square brackets in eq.(4) depends on the level of auditors' liability $\mathrm{P}$. It is negative when $\mathrm{P}$ is relatively high: $\mathrm{P} i \frac{\mathrm{T}+\mathrm{S}}{\mathrm{ft}}+\mathrm{c} \mathrm{F}$ : When the latter inequality is satisfied, the net yield associated with auditors' erroneous certifications is positive, and can be used to partially refund the audit fees borne by non-liable taxpayers.

We can now use the results just obtained to perform some simple comparative statics.

Let us consider how the net revenue is affected by an increase in the taxpayer's penalty. Differentiation of eq. (4) and simplification yields

$$
\frac{a R^{\Lambda}}{(\mathrm{aF}}=\frac{(1 \Gamma \mathrm{p}) \mathrm{ff}}{\mathrm{T} \Gamma \mathrm{ffF}+\mathrm{s}} \mathrm{fi}^{\Lambda}\left(1 \Gamma \mathrm{a}^{\Lambda}\right) \mathrm{ff}(\mathrm{P} \Gamma \mathrm{c}) \text {; }
$$


and, hence,

$$
\frac{\mathrm{aR}^{\Lambda}}{\mathrm{aF}} i 0, \quad \mathrm{P}_{i} \mathrm{c}:
$$

An increase in the taxpayer's penalty reduces the auditors' investigative effort and increases the net recovery associated with tax agency's audits. The overall effect on the net revenue is positive only if the auditor's liability is greater than tax agency's marginal auditing cost. When this condition is not satisfied, the reduction in the screening power of the auditor's services due to more superficial auditing outweighs the saving in private audit costs, with the effect of reducing the tax agency's net revenue.

Let us consider the effect of a variation in the auditor's liability. In order to do so, it is convenient to rewrite the net revenue expression taking into account that at the (interior) equilibrium $\Pi^{0}\left(a^{\Lambda}\right)=0$; and thus $(1 \Gamma \mathrm{p}) \mathrm{fi}^{\Lambda}(f \mathrm{P} \Gamma \mathrm{s})=\mathrm{ps}$. Upon simplification, we get

$$
\mathrm{R}^{\Lambda}=(1 \Gamma \mathrm{p}) \mathrm{T} \Gamma \operatorname{peff} \Gamma \mathrm{a}^{\Lambda} \mathrm{ps} \Gamma(1 \Gamma \mathrm{p}) \mathrm{fi}^{\Lambda}\left(1 \Gamma \mathrm{a}^{\Lambda}\right)[\mathrm{T} \Gamma \mathrm{ffF}+\mathrm{cff}]:
$$

Differentiation with respect to $\mathrm{P}$ yields therefore

$$
\frac{\mathrm{R}^{\Lambda}}{\mathrm{aP}}=\frac{\mathrm{aR}^{\Lambda} \Lambda_{\mathrm{af}} \Lambda}{\mathrm{aP}}=\Gamma(1 \Gamma \mathrm{p})\left(1 \Gamma \mathrm{a}^{\Lambda}\right)[\mathrm{T} \Gamma \mathrm{ffF}+\mathrm{cff}] \Gamma \frac{\mathrm{sff}}{(\mathrm{ffP} \Gamma \mathrm{s})^{2}} \text { \& } 0:
$$

An increase in the auditor's liability makes misreports more costly: auditors are willing to invest more in auditing and liable taxpayers reduce their demand for audits. As a result, correct self-reporting is fostered and the net revenue is increased.

The piece of information just obtained can be used for a simple exercise: suppose that the joint liability for a misreport is fixed, and that it can be apportioned between the taxpayer and the auditor. By comparing eqs. (5) and (7), one can note that

$$
\frac{\mathrm{aR}^{\Lambda}}{\mathrm{aP}} i \frac{\mathrm{aR}^{\Lambda}}{\mathrm{aF}}, \quad[\mathrm{T} \Gamma \mathrm{ff}(\mathrm{F}+\mathrm{P})+\mathrm{cff}+\mathrm{s}] \dot{i} 0 \text { : }
$$

Hence, given a fixed joint liability, an increase in the auditor's liability share increases the tax agency's net revenue if and only if the joint liability is relatively small: $\mathrm{P}+\mathrm{F}$ i $\frac{\mathrm{T}+\mathrm{s}}{\mathrm{ff}}+\mathrm{c}$ :

Let us now consider the effect of a variation in the cost of a private audit. An increase in s has the following implications: it raises the market price of the audit services and the number of liable taxpayers demanding an audit service, while it reduces the level of audit effort exerted by the auditor. From eq.(6), we have

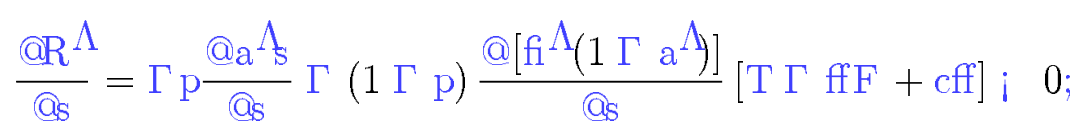




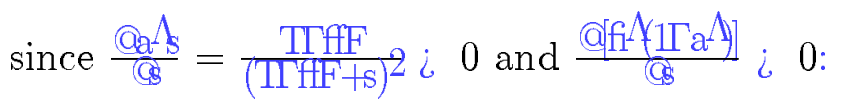

This result has the following implication: if different groups of taxpayers were subject to mandatory auditing, the category with the lowest audit cost would be associated with the smallest audit price, the smallest fraction of misreports and the largest net revenue.

Finally, it can be shown that while an increase in the tax agency's audit cost c clearly reduces the net revenue, variations in the tax agency's audit rate ff and in the $\operatorname{tax} \mathrm{T}$ have ambiguous effects.

To sum up, we have:

Proposition 2 The net revenue increases with an increase in auditors' penalty $\mathrm{P}$; with an increase in taxpayers' penalty $\mathrm{F}$ when $\mathrm{P} \& \mathrm{c}$; with a reduction in the auditor's (marginal) audit cost $s$; and with a reduction in the tax agency's marginal audit cost $c:$

\section{Comparison of regimes}

Let us briefly compare different enforcement regimes. We are interested in establishing the conditions under which gatekeeping can represent an improvement upon (imperfect) public enforcement. It is clear from Proposition 1 that if the tax agency's control rate were so large as to fully deter evasion (ff $i \frac{T}{F}$ ) or so low as not to motivate auditors $\left(\mathrm{ff}_{i} \frac{\mathrm{S}}{(\mathrm{L} \mathrm{p}) \mathrm{P}}\right)$, then gatekeeping would be useless. We consider therefore the intermediate case in which tax agency's control rate lies between $\left(\frac{\mathrm{S}}{\mathrm{S}} \mathrm{p}\right) \mathrm{P}$ and $\frac{\mathrm{T}}{\mathrm{F}}$ :

Social welfare is calculated in a simple utilitarian way by adding the expected costs and benefits accruing to all players, where the expected loss of liable taxpayers is scaled down by a factor ${ }^{`} i$; so as to provide a rationale for the tax system.

In the gatekeepers regime, social welfare amounts to

$$
\begin{aligned}
W^{G}= & \Gamma^{\sim}(1 \Gamma p) T+R^{\Lambda}= \\
& (1 \Gamma p) T\left(1 \Gamma^{\cup}\right) \Gamma \operatorname{pcff} \Gamma a^{A} \operatorname{ps} \Gamma(1 \Gamma p) f^{\Lambda}\left(1 \Gamma a^{\Lambda}\right)[T \Gamma f f F+c f f]:
\end{aligned}
$$

In the absence of a market for audit certificates, pure public enforcement yields:

$$
\mathrm{R}^{\mathrm{P}}=(1 \Gamma \mathrm{p}) \mathrm{ffF} \Gamma \mathrm{cff}
$$

Social welfare is therefore

$$
\mathrm{W}^{\mathrm{P}}=(1 \Gamma \mathrm{p}) \mathrm{ffF}\left(1 \Gamma^{\sim}\right) \Gamma \mathrm{cff}:
$$


Hence, upon simplification,

$$
\begin{aligned}
& W^{G} \Gamma W^{P}=(1 \Gamma p)\left[1 \Gamma f i\left(1 \Gamma a^{\wedge}\right)\right](T \Gamma f f F) \Gamma{ }^{\bullet}(1 \Gamma p)[T \Gamma f f F] \\
& +(1 \Gamma \mathrm{p})\left[1 \Gamma \text { fi }\left(1 \Gamma \mathrm{a}^{\mathrm{A}}\right)\right] \mathrm{cff} \Gamma \mathrm{a} \text { As: }
\end{aligned}
$$

The introduction of mandatory gatekeeping affects social welfare through the following effects: a) tax evasion is reduced, b) liable taxpayers lose their evasion rent, c) gatekeepers' screening services reduce tax agency's enforcement cost, and d) additional audit costs are borne by the private sector.

It cannot be said a priori whether the introduction of gatekeepers increases or reduces social welfare. This will depend, in general, on the configuration of the enforcement parameters, and in particular on the level of private audit cost and auditors' liability. From the comparative static results of section 2, it can easily be seen that

$$
\frac{{ }^{1} W^{G} \Gamma W^{P^{j}}}{@_{S}} ; 0 \text { and } \frac{{ }^{1} W^{G} \Gamma W^{P^{j}}}{@ P} ; 0 \text { : }
$$

Hence, the introduction of gatekeeping is more likely to increase social welfare when the private audit cost is smaller and auditors' liability is higher.

If we consider the limit case in which the private audit cost is close to nought, s! 0 ; we get

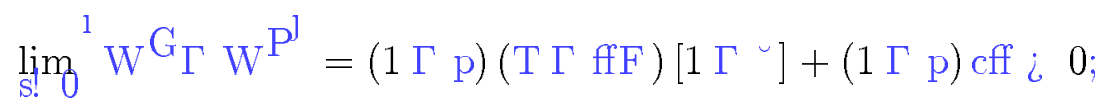

since $\lim _{\mathbb{s}}$ ! $0 \mathrm{fi}^{\Lambda}=0 ; \lim _{\mathrm{s}} ! 0 \mathrm{a}^{\Lambda}=1$; and $\lim _{\mathrm{s}}$ ! $0 \mathrm{q}^{\Lambda}=0$ :

On the other hand, if auditors were infinitely liable, we would have limp! $1 f^{\Lambda}=0$, $\operatorname{limP!} 1 \mathrm{a}^{\Lambda}=\frac{\mathrm{T} f \mathrm{fF}}{\mathrm{T} \text { fff }+\mathrm{s}} ;$ and $\operatorname{limP!} 1 \mathrm{q}^{\Lambda}=\mathrm{s}$; and hence

$$
\lim ^{1}{ }^{1} \mathrm{~W}^{\mathrm{G}} \Gamma \mathrm{W}^{\mathrm{P}}=(1 \Gamma \mathrm{p})(\mathrm{T} \Gamma \mathrm{ffF})\left[1 \Gamma^{\sim}\right]+(1 \Gamma \mathrm{p}) \operatorname{cff} \Gamma \mathrm{a} \mathrm{ps} \text {; }
$$

which cannot be unambiguously signed. The introduction of gatekeepers with infinite liability is desirable if and if only the gains associated with the reduced evasion and the screening of taxpayers outweigh the cost of private auditing.

To sum up:

Proposition 3 If $\underset{(I \mathrm{p}) P}{\mathrm{~s}} \mathrm{i}$ ff $i \frac{\mathrm{T}}{\mathrm{F}}$; the introduction of mandatory gatekeeping is socially desirable if and only if the following inequality is satisfied

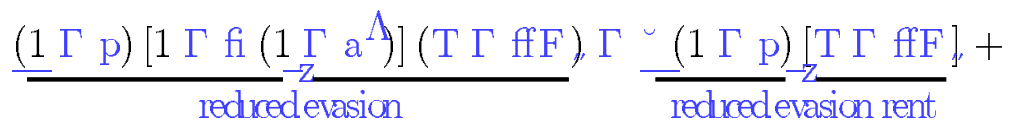

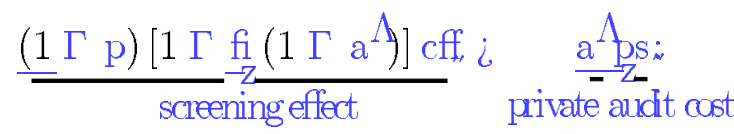


Gatekeeping is more likely to be socially desirable when the private audit cost is smaller and the auditors' liability is higher. If private audit cost is negligible, s! 0; gatekeeping is definitely desirable. If the auditors' liability is extended to infinity, P ! 1 ; gatekeeping is desirable if and only if

$$
(1 \Gamma \mathrm{p})(\mathrm{T} \Gamma \mathrm{ffF})\left[1 \Gamma^{\lrcorner}\right]+(1 \Gamma \mathrm{p}) \mathrm{cff} \sim \mathrm{a}^{\wedge} \mathrm{ps}:
$$

This result shows that the desirability of a gatekeeping system depends on many factors. In particular, successful gatekeeping seem to be associated with: 1) the inability of the public enforcer to produce sufficient deterrence, 2) a high liability for inaccurate auditing, and 3) a low private audit cost. In the appendix, we check whether conditions 2 and 3 retain their force when the public enforcer is able to produce full deterrence (ff can be suitably adjusted). We show that when s tends to nought, the tax agency can indeed achieve the first best (collecting taxes due at no cost). On the other hand, when the auditor's liability is stretched to infinity (and auditors' reports are turned into "hard evidence"), gatekeeping is desirable only if the "cost to sanction" ratio is smaller under private rather than public auditing (which can occur only if private auditors are relatively more efficient in auditing, s i c): This result seem to endorse the view that the real strength of a gatekeeping system lies in the informational advantages of gatekeepers rather than in the extension of the compounded liability for misconduct (deep-pockets theory).

\section{Extensions}

In the following sections, we extend the basic model so as to take into account the effects of: a) the possibility of collusion between auditors and taxpayers, b) a tighter liability rule for auditors, c) further delegation of enforcement powers, and d) cartelization of the audit market.

\subsection{Collusion}

The fact that the relationship between auditors and taxpayers is mediated by the market does not preclude the possibility of collusive agreements between the two parties. Indeed, auditors may find it profitable to sell non-liability certifications on the spot, without bothering to investigate the taxpayer's real type. Also, after discovering one taxpayer's true liability, auditors may accept a bribe in exchange for a cover-up. 14

\footnotetext{
${ }^{14}$ The problem of collusion between auditors and auditees has been examined, among others, by Baiman, Evans and Nagarajan (1991), Tirole (1992), and Kofman and Lawarre (1993).
} 
In the simple model outlined in this paper, collusion can be prevented by an appropriate specification of the liabilities of the taxpayer and the auditor. In essence, joint liability has to be set to such a high level as to make side-dealing unprofitable.

Consider first the possibility of ex-ante collusion. The price b of a "spot" liability certificate cannot be less than the expected penalty for the auditor: $b{ }^{\sim}$ ffP: Collusion can then be prevented by setting $\mathrm{P}$ and $\mathrm{F}$ so high as to make the expected payment for the taxpayer with collusion greater than the expected payment without collusion: $(b \Gamma q+f f F) i(1 \Gamma a) f f F+a(T+q)$ : Since in equilibrium, $q=s$ and $(1 \Gamma a) f f F+$ $\mathrm{a}(\mathrm{T}+\mathrm{q})=\mathrm{T}$; the previous inequality reduces to $(\mathrm{b} \Gamma \mathrm{s}+\mathrm{ffF}) \dot{\mathrm{T}} \mathrm{T}$; which is surely satisfied when ffP $+f f F \& T+s ;$ i.e. when the joint cost of collusion exceeds the joint gain. 15

For the case of ex-post collusion, the bribe for an auditor who has detected a misreport cannot again be less that ffP: Also, the expected payment for the taxpayer is $\mathrm{b} \Gamma \mathrm{q}+\mathrm{ffF}$ if he colludes, and $\mathrm{T}$ if he does not. Hence, the collusion-proof liability level is the same as before.

Proposition 4 Collusion between the taxpayer and the auditor is prevented when their joint liability is sufficiently high: $\mathrm{P}+\mathrm{F} i \frac{\mathrm{T}+\mathrm{S}}{\mathrm{ff}}$ :

\subsection{Strict liability versus negligence}

In this section we consider the somehow less realistic case in which the auditor's investigation procedure is perfectly revealed by the tax agency's audit. In other words, by spending some resources, the tax agency can observe ex-post whether the auditor has exerted effort in auditing, and can sanction it for inaccurate auditing even if the audit outcome is correct (the taxpayer is really non-liable). In practice, this means that the auditing procedure can be broken down into a certain number of steps, which allow the auditor to determine without uncertainty the characteristics of the taxpayer. These steps are essentially those which characterize the procedure followed by the tax agency or the courts, and which define the legal "truth" about individual situations. In this setting, the auditor's report to the tax agency is not restricted to the Liable - Non liable alternatives, but involves all numerable characteristics of the taxpayers that define his type. The agency's audit reveals whether these characteristics are correctly assessed, i.e. whether "due care" has been exerted in auditing. 16

\footnotetext{
15 To be certain, this proves that the equilibrium identified in section 2 remains such even when the possibility of collusion is taken into consideration. We have not proved that other (collusive) equilibria can not emerge.

${ }^{16}$ The analysis can be easily extended to the case in which "due care" is defined by Generally Accepted Accounting Standards that leave a margin of uncertainty in the determination of taxpayers'
} 
The standardized auditing procedure imposes a (possibly high) cost $\mathrm{s}$ on the auditor; which may discourage accurate auditing. We will assume, again, that the tax agency plays the role of the watchdog, performing random controls on certified taxpayers.

Let us consider the auditors' optimal decision in the new set-up. Let a be the probability that the auditor follows the standardized procedure. The probability that the taxpayer's type is discovered is hence equal to a: With probability $1 \Gamma$ a the auditor discovers nothing and makes her report up (by picking at random a type in the non-liability region).

The net profit of the auditor is defined as

$$
\Pi_{\mathrm{N}}=\mathrm{q} \Gamma \text { sa } \Gamma(1 \Gamma \text { a) ffP; }
$$

where $q$ represents the market audit fee, sa the expected audit cost and ( $1 \Gamma$ a) ffP the expected sanction following a failure to discover the truth. Contrary to the expression of Section 2, here the expected sanction is not scaled down by the probability that the taxpayer is actually liable: whatever the taxpayer's true liability level, the auditors can be sanctioned for negligent auditing.

Maximization of (8) with respect to a yields:

$$
\begin{aligned}
& 8 \text {; } A \hat{1}=0 \quad \text { if } \operatorname{ffP}_{i} \mathrm{~s} \text {; }
\end{aligned}
$$

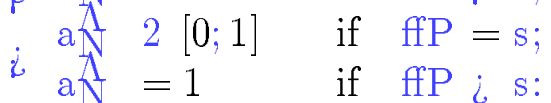

The auditor's decision is effectively decoupled from that of the taxpayer. It depends only on the prospective punishment threatened by the tax agency in case of negligent auditing.

Profits for the auditor will therefore be

$$
\Pi \hat{\Lambda}=\begin{array}{ll}
q \Gamma f P & \text { if } f P \sim s ; \\
q \Gamma s & \text { if } f P i s:
\end{array}
$$

In view of the price competition between auditors, the equilibrium level of the audit fee will hence be

$$
q A=\begin{array}{ll}
\text { ffP } & \text { if } f f P \\
s & \text { if }
\end{array}
$$

We can now turn to taxpayers. Since liable taxpayers elect to demand a certification only if a is sufficiently small, we have

$$
\begin{aligned}
& 8 \text { fî }=0 \quad \text { if } \mathrm{fPP}_{i} \mathrm{~s} \text {; } \\
& \text { fif } 2[0 ; 1] \text { if } \mathrm{ffP}=\mathrm{s} \text {; } \\
& \dot{\mathrm{fiN}}=1 \text { if } \mathrm{ffP} ; \mathrm{s} \text { : }
\end{aligned}
$$

true characteristics. 
It can be seen, therefore, that the enforcement outcome depends ultimately on the level of the expected punishment for negligent auditing by the auditor.

For ffP $i$ s (negligent auditing is deterred), the net revenue to the tax agency is

$$
\mathrm{R} \hat{\wedge}=(1 \Gamma \mathrm{p}) \mathrm{T} \Gamma \mathrm{ps} \Gamma \mathrm{peff}
$$

With a negligent liability standard, auditors are more easily motivated to perform a thorough audit, since correct reporting by the taxpayer cannot be an excuse for their inaccurate auditing. Hence, they cannot rely on their equilibrium beliefs to fill in their report.

If we compare the net revenues obtained under strict liability and negligence standard (eq.(4) and (9), respectively), we get

$$
\mathrm{RAi}_{\mathrm{i}} \mathrm{R}^{\Lambda}, \quad \mathrm{P}+\mathrm{F} i \frac{\mathrm{T}+\mathrm{s}}{\mathrm{ff}}+\mathrm{c}
$$

that is, a tight negligence standard is desirable only if the auditor's and taxpayer's joint liability is relatively small.

To sum up:

Proposition 5 Auditors' liability standard. Assume that the auditors' message space is wider than that of the taxpayer and that auditors' liability concerns the respect of proper auditing standards rather than correct certification (the auditor is subject to a tight negligence standard). Then, if the auditor's liability is sufficiently high, $\mathrm{P}$ i sff; the auditors perform accurate auditing, $\mathrm{a}^{\Lambda}=1$; liable taxpayers do not demand a non-liability certificate, $\mathrm{fi}^{\Lambda}=1$; and the audit fee is fixed at $\mathrm{q}^{\Lambda}=\mathrm{s}$ :

A tight negligence standard is preferable to a strict liability standard only when the joint liability is relatively small: $\mathrm{P}+\mathrm{F} i \frac{\mathrm{T}+\mathrm{S}}{\mathrm{ff}}+\mathrm{c}$ :

Under a tight negligence standard, the risk of a sanction for inaccurate auditing is increased, and auditors are lead to provide high quality audits. Auditors' accurate screening services, however, are costly: no sanctions are ever collected on auditors, and liable taxpayers do not contribute to the refunding of the audit expenses of the non-liable ones. Whether such a high auditing effort is actually desirable depends on the accuracy reached under the strict liability standard: when the joint liability is high, liable taxpayers are motivated to self-report correctly and auditors have enough incentives to perform audits of good quality even if they are not subject to a tight negligence rule. Hence, there is no need to force auditors to further increase the quality - and cost - of their audits. 


\subsection{Gatekeeping versus full delegation}

In a gatekeepers' regime, third-party enforcement aims at preventing misconduct by agents subject to a specific law. Third party enforcement, however, can take even stronger forms, in which the third party is empowered with the faculty to enforce the law and impose sanctions on noncompliant agents. In this section, we enhance the auditors' position in the enforcement system by making misreports to the auditor unlawful, and hence punishable. We model this possibility by assuming that liable taxpayers detected by the auditor have to pay, on top of $\mathrm{q}+\mathrm{T}$; an extra penalty $\mathrm{B}$; which is collected by the tax agency. When the total payment $q+T+\beta$ reaches the maximal penalty $\mathrm{F}$; enforcement is de facto delegated to auditors, who are in charge of detecting acts of misconduct (lying to the auditor is equivalent to lying to the tax agency) and reporting them to the authority.

Apart from this, the structure of the game remains unaltered: taxpayers demand audits on the audit market, auditors compete à la Bertrand, and misreports detected by the tax agency lead to a sanction of both the taxpayer and the auditor. ${ }^{17}$

In the (interior) equilibrium, the demand for audits by liable taxpayers and the market audit fee are the same as in section 2, while audits' quality becomes

$$
a_{f}^{A}=\frac{T \Gamma f f F}{T \Gamma f f F+s+\beta}:
$$

The imposition of a penalty on taxpayers who misreport to their auditor allows the latter to reduce their investigative effort. The net revenue to the tax agency is now

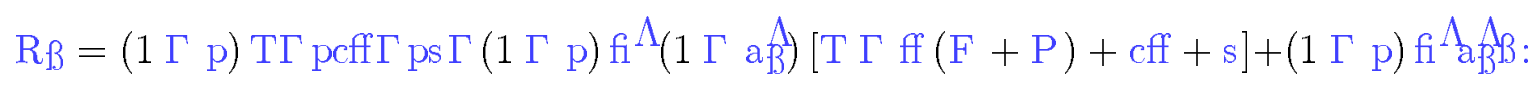

Through algebraic manipulation it can be shown that

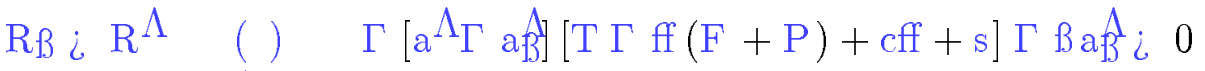

$$
\begin{aligned}
& \text { ( ) } \mathrm{P} i \mathrm{c} \text { : }
\end{aligned}
$$

Hence, the additional sanction $\beta$ increases the tax agency's net revenue only if the auditors' liability is sufficiently high. Since in the new equilibrium both the taxpayers' expected payments and auditors' net profits are unaltered, variations in the net revenue translate directly into variations in social welfare. This allows us to conclude as follows.

\footnotetext{
${ }^{17}$ It may seem odd that taxpayers are requested to pay for an auditing service that is apparently not to their advantage. This, however, is only due to an accounting convention: taxpayers who obtain a non-liability certificate have their audit fees refunded, while the others pay a sanction which is net of the fee. It is the tax agency which ultimately bears the cost of private enforcement.
} 
Proposition 6 Full delegation. The introduction of a sanction for taxpayers who misreport to their auditor is socially desirable if and only if auditors' liability exceeds the public audit cost: $\mathrm{P} \& \mathrm{c}$ :

This results shows that the reduction in private auditing effort is socially desirable only if the net yield of public audits from (undetected) liable taxpayers is sufficiently large. Under this condition, which also guarantees that $\frac{\mathrm{aR}}{\mathrm{d} F} \dot{i} 0$, it is desirable to increase taxpayers' incentives to correctly self-report, so as to minimize the amount of social resources devoted to auditing.

\subsection{Cartelization in the audit market}

A particular difficulty which an efficient gatekeeping system may have to surmount is represented by gatekeepers' tendency to group in professional associations and create market barriers. This tendency may result in the creation of a gatekeepers' "cartel," able to exercise monopoly power on the audit market. This possibility is clearly deleterious for the enforcement system, and can make gatekeeping definitely undesirable.

In order to provide a formal foundation to the previous argument, let us consider the optimal pricing policy for monopolistic gatekeepers. In the move sequence, the gatekeepers' association is now assigned the first move (set the audit fee). Apart from this, the move order is the same as before.

The profit of each auditor is given by

$$
\Pi d=q \Gamma \operatorname{sad} \Gamma\left(1 \Gamma \text { ad) } \frac{(1 \Gamma p) f i d}{(1 \Gamma p) f i d+p} f f P\right.
$$

where a $\mathrm{C}$ and $\mathrm{fi}$ are determined in the continuation equilibrium. For the same arguments given in Section 2, it can be seen that in the continuation equilibrium both taxpayers and auditors will play mixed strategies (assuming that $(\Pi \mathrm{S}) \mathrm{P}$ i ff $\frac{T}{\mathrm{~F}}$ ):

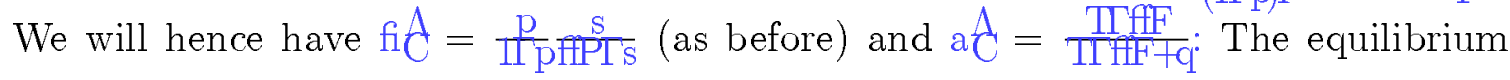
audit quality is hence decreasing in q:

Differentiation of the profit function yields

$$
\Pi_{\mathrm{q}}^{20}=\frac{\mathrm{d} \Pi}{\mathrm{dq}} \Gamma \frac{\mathrm{a}_{\mathrm{q}}}{\mathrm{a}_{\mathrm{a}}} \frac{\mathrm{a}_{\mathrm{a}} \Lambda}{\mathrm{a}_{\mathrm{q}}}=1 ;
$$

since in equilibrium $\frac{a}{a}=0$. Ergo, gatekeepers have an incentive to set the audit fee as high as possible, $q^{\Lambda}$ ! 1 ; thereby pushing the equilibrium audit quality to nought. Under these conditions gatekeeping would be definitely detrimental, as it would just provide gatekeepers with a position rent. 
In an attempt to restrain gatekeepers' monopolistic ambitions, a price-cap on the audit fee may be imposed. As expected, the net revenue to the tax agency is larger if the cap is smaller. Depending on the level of this cap (as well as on the weight attached to auditors' profits in the social welfare function), gatekeeping may or may not be socially desirable.

\section{$5 \quad$ Final remarks}

The model developed in this paper sheds some light on the implications of gatekeeping on the behavior of the agents and the enforcement of law. Despite its simplicity, the model provides clear-cut criteria for the assessment of gatekeeping systems, and a rationale for some of those already in place. Gatekeeping turns out to play a role in enforcement only if public enforcement is insufficient, but not immaterial, as otherwise gatekeepers would not be induced to perform accurate audits. Under this condition, gatekeeping is proved to be socially desirable only if the private audit cost is smaller that the public one and auditors' liability is sufficiently high.

The basic model is helpful in shedding light on some important issues related the optimal enforcement system. In particular, we have shown that, when the joint liability of the auditor and the taxpayer is sufficiently high, collusion between them should not represent a threat to the proper functioning of the gatekeeping system and that a strict negligence standard (whereby auditors are liable whenever their report is incorrect) should yield the best outcome. Also, we have proved that further delegation of the enforcement powers to private auditors would be desirable, provided that the gatekeepers' liability is sufficiently high. Finally, we have identified what is likely to represent the major threat to a gatekeeping system, namely the possible cartelization of the gatekeepers' market, which would definitely call for some form of public regulation.

Our analysis can be extended in several ways. First, it may be interesting to consider the possibility that auditors' reports address both by the public enforcer and a private "principal" (e.g. the capital market), who is also interested in knowing the agent's true characteristics. Indeed, in many settings, the information upon which the tax liability is defined affects other important aspects of an agent's activity, like its solvency and profitability. It is not clear, at this stage, how the introduction of this common agency problem would affect our results.

Second, we have only mentioned the possibility that the gatekeeping duty is assigned to taxpayers' legal advisors, who usually have a good knowledge of taxpayers' real situation. Bundling legal counseling and gatekeeping together, as it often occurs 
in real practice, may be an effective tool to reduce the gatekeeping costs (thanks to an economy of scope), but may also have negative consequences on the fiduciary relation between advisors and their clients. Given its relevance in real gatekeeping systems, this issue probably deserves a more accurate investigation. 


\section{Appendix}

One may wonder how the desirability of a gatekeeping regime relates to the assumption that direct public enforcement is unable to produce deterrence, i.e. that $\mathrm{ff}$ is bounded above. In this appendix, we consider the case in which the tax agency can suitably adjust the control rate ff; and derive the enforcement outcome for the limit cases in which s! 0 and P! 1 :

Suppose that ff can be set to any level. Under the (reasonable) assumption that $(1 \Gamma \mathrm{p}) \mathrm{F} \& \mathrm{pc}$; the optimal control policy under direct public enforcement is $\mathrm{ff}=$ $\operatorname{limffl} 0 \frac{T}{\mathrm{~F}}+$ ffll which yields $\mathrm{R}=(1 \Gamma \mathrm{p}) \mathrm{T} \Gamma \mathrm{pc} \frac{\mathrm{T}}{\mathrm{F}}$ :

Consider now the optimal gatekeeping policy. Let $\mathrm{s} ! 0$ : Since $\lim _{\mathrm{s}}$ ! $0 \frac{\mathbb{R} A}{\mathrm{CAf}}=$ Грс $i \quad 0$; the tax agency will optimally set ff ! 0 and net: $\lim _{s} ! 0 R^{\Lambda}=(1 \Gamma p) T$ : Hence, the first best is achieved: audit costs are reduced to nought and taxes are collected in full. The possibility of involving an informed third party in the enforcement system allows the agency to overcome its limited information and to avoid wasting any resources in costly auditing.

Suppose now that auditors are assigned an infinite liability. Under this condition,

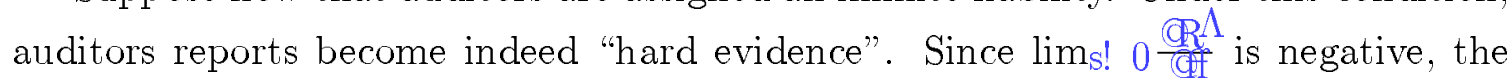
tax agency will set ff! 0 and obtain (see eq.4) limp! $1 R^{\Lambda}=(1 \Gamma \mathrm{p}) \mathrm{T} \Gamma \mathrm{ps} \frac{\mathrm{T}}{\mathrm{T}+\mathrm{s}}$ : In equilibrium, therefore, some resources are still spent in auditing and the first best is not achieved. If we compare this expression with the outcome associated with optimal public enforcement, we get

$$
W^{G} W^{P}, \frac{s}{T+s} i \frac{c}{F}
$$

which says that the comparison between the two enforcement system depends on the relative levels of the "cost-sanction ratio," i.e. the ratio between the audit cost (s and c; respectively) and the "sanction" to taxpayers following an adverse audit outcome $(\mathrm{T}+\mathrm{s}$ and $\mathrm{F}$; respectively). Since $\mathrm{T}+\mathrm{s} \sim \mathrm{F}$ by the limited liability of taxpayers (the optimal fine expropriates the taxpayers of his entire asset), it follows that: Even when the auditor's liability is stretched to infinity (auditor's reports are "hard evidence"), gatekeeping is desirable only if private auditors are more efficient in auditing: s i c: ${ }^{18}$

\footnotetext{
${ }^{18}$ It can be shown that the same result obtains when auditors are protected by limited liability $(\mathrm{P} ; \infty)$ and are offered an infinite reward for each case of misreporting detected.
} 


\section{References}

Baiman, S., J. Evans, and N. Nagarajan, 1991, Collusion in auditing, Journal of Accounting Research 29, 1-18.

Baiman, S., J. Evans, and J. Noel, 1987, Optimal contracts with a utility-maximizing auditor, Journal of Accounting Research 25, 217-244.

Becker, G. and G. Stigler, 1974, Law enforcement, malfeasance, and compensation of enforcers, Journal of Legal Studies 3, 1-18.

Developments in the law, 1994, Lawyers' responsibilities and lawyers' responses, Harvard Law Review 107, 1547-1674.

Dye, R., 1993, Auditing standards, legal liability, and auditor wealth, Journal of Political Economy 101, 887-915.

Eörsi, G., 1975, Private and Governmental Liability for the Torts of Employees and Organs, chap. 4, vol. 11, International Encyclopedia of Comparative Law, Mouton, The Haugue.

Friedman, D., 1984, Efficient institutions for the private enforcement of law, Journal of Legal Studies 13, 379-398.

Gjesdal, F., 1981, Accounting for stewardship, Journal of Accounting Research 19, 208-231.

Kaplow, L. and S. Shavell, 1994, Optimal law enforcement with self-reporting of behaviour, Journal of Political Economy 102, 583-606.

Klepper, S. and D. Nagin, 1989, The role of tax preparers in tax compliance, Policy Sciences 22, 167-194.

Klepper, S., M. Mazur, and D. Nagin, 1991, Expert intermediaries and legal compliance: the case of tax preparers, Journal of Law and Economics 34, 205-229.

Kofman, F. and J. Lawarrée, 1993, Collusion in a hierarchical agency, Econometrica $61,629-656$.

Kraakman, R., 1984, Corporate liability strategies and the costs of legal control, The Yale Law Journal 93, 857-898.

Kraakman, R., 1986, Gatekeepers: the anatomy of a third-party enforcement strategy, Journal of Law, Economics, and Organization 2, 53-104.

Landes, W. and R. Posner, 1975, The private enforcement of law, Journal of Legal Studies 4, 1-18.

Melumad, N. and D. Mookherjee, 1989, Delegation as commitment: the case of income tax audits, RAND Journal of Economics 20, 139-163.

Narayan, V.G., 1994, An analysis of auditor liability rules, Journal of Accounting Research 32, 39-65.

Polinsky, M., 1980, Private versus public enforcement of fines, Journal of Legal Studies 9, 105-127. 
Polinsky, M. and S. Shavell, 1984, Optimal use of fines and imprisonment, Journal of Public Economics 24, 89-99.

Reinganum, J. and L. Wilde, 1985, Income tax compliance in a principal-agent framework, Journal of Public Economics 26, 1-18.

Reinganum, J. and L. Wilde, 1991, Equilibrium enforcement and compliance in the presence of tax practitioners, Journal of Law, Economics and Organization 7, $163-181$.

Schotchmer, S., 1989, The effect of tax advisors on tax compliance, in Taxpayer compliance, vol. II, edited by J. Roth and J. Scholz, University of Pennsylvania Press, Philadelphia.

Strausz, R., 1995, Delegation of monitoring in a principal-agent relationship, w.p. \#60, CentER for Economic Research, Tilburg University.

Sykes, A., 1981, An efficiency analysis of vicarious liability under the law of agency, The Yale Law Journal 91, 168-206.

Sykes, A., 1984, The economics of vicarious liability, The Yale Law Journal 93, 1231-1280.

Sykes, A., 1988, The boundareis of vicarious liability: an economic analysis of the scope of the employment rule and related legal doctrines, Harvard Law Review $101,563-609$.

Tirole, J., 1992, Collusion and the theory of organizations, in Advances in Economic Theory, vol. II, edited by J.J. Laffont, C.U.P., Cambridge.

Toma, E.F. and M. Toma, 1992, Tax collection with agency costs: private contracting or government burocrats?, Economica 59, 107-120. 